A FUNÇÃO DA DEFENSORIA PÚBLICA NA IMPLEMENTAÇÃO DE DIREITOS HUMANOS À POPULAÇÃO LGBTI

Emanuel Adilson Gomes Marques

THE ROLE OF THE PUBLIC DEFENDER'S OFFICE IN THE IMPLEMENTATION OF HUMAN RIGHTS TO THE LGBTI POPULATION 


\section{A FUNÇÃO DA DEFENSORIA PÚBLICA NA IMPLEMENTAÇÃO DE DIREITOS HUMANOS À POPULAÇÃO LGBTI}

THE ROLE OF THE PUBLIC DEFENDER'S OFFICE IN THE IMPLEMENTATION OF HUMAN

RIGHTS TO THE LGBTI POPULATION

Emanuel Adilson Gomes Marques

Defensor Público Federal

Meste em Direito pela Universidade Nove de Julho

São Paulo, Brasil.

emanuel.marques@dpu.def.br

\section{RESUMO}

Esta pesquisa analisa a função da Defensoria Pública na implementação de Direitos Humanos à população LGBTI (Gays, Lésbicas, Bissexuais, Transexuais, Intersex), objetivando cumprir a missão constitucional de garantir os princípios de acesso à justiça e de igualdade entre as partes, de comprometimento com a democracia e com a construção de uma sociedade mais justa e solidária. Buscou-se analisar as açóes efetivas que os Defensores Públicos podem utilizar para implementar políticas públicas que busquem garantir a este público direitos consagrados internacionalmente. Este estudo adota o método dedutivo de abordagem e pesquisa documental e bibliográfica como técnicas de pesquisa.

Palavras-chave: Direitos humanos internacionais. População lésbica, gay, bissexual, transexual e intersex (LGBTI). Organização das Naçôes Unidas. Organização dos Estados Americanos. Defensoria Pública. 


\section{ABSTRACT}

This research analyzes the function of the Brazilian Public Defender's Office in the implementation of Human Rights to the LGBT population (Gay, Bisexual, Lesbian, Transgender, Intersex), aiming to fulfill the constitutional mission of ensuring the constitutional principles of access to justice and equality between the parties, of commitment with democracy and building a more just and united society. The aim is to analyze the effective action that the public defenders can use to implement public policies that seek to ensure that public rights recognized internationally. This study adopts the deductive method of approach and documentary and bibliographic research, as research techniques.

Keywords: International human rights. Population lesbian, gay, bisexual, transgender and intersex (LGBTI). United Nations Organization; Organization of American States. Public Defense.

Data de submissão: 14/03/2016

Data de aceitação: 24/08/2017

\section{SUMARIO}

INTRODUÇÃO 1. SISTEMA DE DIMENSÓES DOS DIREITOS HUMANOS

2. SISTEMA INTERNACIONAL DE DIREITOS HUMANOS LGBTI - ONU

3. SISTEMA INTERAMERICANO DE DIREITOS HUMANOS E DIREITOS LGBTI - OEA 4. DEFENSORIAS PÚLICAS NO BRASIL E DIREITOS INTERNACIONAIS CONSAGRADOS A POPULAÇÃO LGBTI. CONSIDERAÇÓES FINAIS.

\section{INTRODUÇÁO}

Neste artigo, pretende-se analisar como se encontram as políticas de implementação de direitos humanos em prol da população LGBTI no âmbito da Organizaçáo das Naçôes 
Unidas, bem como da Organização dos Estados Americanos. Analisar-se-á quais são as Resoluçôes e Convençôes que as referidas entidades estão buscando para efetivar os direitos às Lésbicas, aos Gays, aos Bissexuais, aos Transexuais e aos Intersex ${ }^{1}$.

No mundo inteiro, as lésbicas, os gays, os bissexuais, os transgêneros e os intersex de todas as idades são alvo de perseguição e descriminação no trabalho, em casa, na escola e em muitas outras situaçôes do dia-a-dia. Em muitos países, a legislação nacional lhes é desfavorável. Em cerca de 76 Estados, ter um parceiro do mesmo sexo constitui crime. Existem pessoas que são detidas, identificadas para serem alvo de agressóes físicas, torturadas ou mesmo assassinadas simplesmente por terem uma relação amorosa.

Quando se afirma tal questão, não se quer defender novos direitos ou direitos especiais para a referida população. O que se pretende é efetivar o que já está consagrado no âmbito dos Direitos Humanos Internacionais: o Direito à vida, à liberdade, à não discriminaçấo, dentre outros, são universais e estão consagrados internacionalmente, mas são muitas vezes negados a muitos dos nossos semelhantes simplesmente devido à sua orientação sexual ou identidade de gênero.

Diante dos dados estatísticos de violência, preconceito, exclusão social das minorias LGBTI, faz-se necessário, no âmbito brasileiro, que entidades governamentais assumam a responsabilidade de implementação de direitos de primeira, segunda e terceira geração.

No Brasil, a Defensoria Pública ganhou legitimidade Constitucional e legal para implementar todas as diretrizes inclusivas determinadas no âmbito internacional para implementação dos referidos direitos. Será demonstrado ao longo do trabalho, como a Defensoria Pública da União está atuando em prol da referida população, bem como os inúmeros avanços a serem conquistados na esfera dos direitos. Entretanto, surgemnos questôes relevantes: será que as Defensorias Públicas estão efetivamente atuando contra o preconceito e, em contrapartida, buscando a inclusão dessas minorias?

Assim, este trabalho terá por objetivo demonstrar inúmeros direitos e garantias que necessitam ser implementados à população LGBTI pela Defensoria Pública Brasileira, cumprindo, destarte, determinações estabelecidas por organismos internacionais.

\footnotetext{
1 Intersex ou intersexo é o termo utilizado para designar a condição em que uma pessoa nasce com a
} anatomia reprodutiva ou sexual que não se encaixa na definição típica de sexo feminino ou masculino. 
A técnica de pesquisa utilizada é a bibliográfica e documental, utilizando-se de estudos jurídicos especializados, estudos científicos transversais, doutrinas, literatura contemporânea sobre pós-modernidade, bem como normas constitucionais.

\section{SISTEMA DIMENSÃO DOS DIREITOS HUMANOS}

Ab initio importante justificar a razão pelo qual os Direitos Humanos são divididos em geraçôes. Com efeito, os Direitos Humanos nascem e se modificam observando o sentimento valorativo da sociedade. De acordo com a historicidade desses direitos, para doutrina majoritária, eles podem ser divididos em três geraçôes. Os direitos humanos de primeira geração foram idealizados para limitar a atuação do Estado, preservando direitos como a liberdade e a segurança.

Neste diapasão, Schäfer:

Natural, portanto, que as primeiras concepçóes formais de direitos tivessem por objetivo a proteção do cidadão frente ao Estado absolutista (Leviatâ, na concepção clássica de Hobbes), pois a liberdade é pressuposto para o exercício de outras faculdades constitucionais. O reconhecimento da existência de direitos irrenunciáveis quando do contrato social fez nascer uma nova relação entre sociedade civil e o Poder Público, estabelecendo uma clara separação entre estas duas importantes estruturas sociais. Essencialmente, preservaram-se situaçóes nas quais não se mostraria lícita a intromissão do Estado nas relaçóes privadas, submetendose o soberano ao império da lei: o Estado somente pode intervir nos direitos dos cidadáos mediante prévia autorização da lei, a qual, fruto do parlamento, representa autorizaçáo do conjunto dos cidadãos, a partir dos primados da democracia representativa ${ }^{2}$.

Posteriormente, advieram os direitos humanos de segunda geraçáo, na qual se objetivava a concessão de direitos econômicos e sociais. De acordo com a doutrina de Celso Lafer:

O elenco dos direitos humanos contemplados pelo Direito Positivo foi se alterando do século XVIII até os nossos dias. Assim caminhou-se historicamente dos direitos humanos de primeira geração - os direitos civis e políticos de garantia, de cunho individualista voltados para tutelar a diferença entre Estado e Sociedade e impedir

2 SCHAFER, J. Classificação dos direitos fundamentais - do sistema geracional ao sistema unitário, p. 19. 
a dissolução do indivíduo num todo coletivo - para os direitos de segunda geraçáo - os direitos econômicos, sociais e culturais concebidos como créditos dos indivíduos com relação à sociedade, a serem saldados pelo Estado em nome da comunidade nacional. O processo de asserção histórica das duas geraçóes de direitos humanos, que são direitos de titularidade individual, foi inspirado pelos legados cosmopolita e universalista do liberalismo e do socialismo. ${ }^{3}$

Por fim, advieram os Direitos Humanos de terceira geração, considerados como direitos de fraternidade, consistindo na tutela da solidariedade. Tais direitos surgiram com o fim da segunda guerra mundial, e a criação da Organização das Naçôes Unidas (ONU) inaugura uma perspectiva de cooperação internacional, na qual o Estado Nação se transforma em Estado Constitucional Cooperativo.

Não se desconhece a crítica realizada pelo autor Antônio Augusto Cançado Trindade, que critica a divisão desses direitos em geraçôes, afirmando que se tratam de dimensóes de direitos, vez que todos eles se somam, se acrescentam ao longo do tempo. Em sua obra Tratado Internacional de Direitos Humanos,

\begin{abstract}
A fantasia nefasta das chamadas 'geraçóes de direitos', histórica e juridicamente infundada, na medida em que alimentou uma visão fragmentada ou atomizada dos direitos humanos, já se encontra devidamente desmistificada. $\mathrm{O}$ fenômeno de hoje testemunhamos não é o de sucessão, mas antes, de uma expansão, cumulação e fortalecimento dos direitos humanos consagrados, consoante uma visão necessariamente integrada de todos os direitos humanos. As razôes histórico-ideológicas da compartimentalização já há muito desapareceram. Hoje podemos ver com clareza que os avanços nas liberdades públicas em tantos países nos últimos anos devem necessariamente fazer-se acompanhar náo de retrocesso - como vem ocorrendo em numerosos países - mas de avanços paralelos no domínio econômico-social. ${ }^{4}$
\end{abstract}

Cumpre-nos destacar que outros autores utilizam a expressão dinamogenese dos direitos humanos, denotando que eles não são imutáveis, variando conforme as circunstâncias sociais do momento histórico em que se manifestam, com respectivo nascimento e desenvolvimento como um processo dinâmico5.

3 LAFER, C. A reconstruçáo dos Direitos Humanos: a contribuição de Hannah Arendt. Disponível em: http://www.scielo.br/pdf/ea/v11n30/v11n30a05.pdf; Acesso em: 14 set. 2016.

4 TRINDADE, A. A. C. Tratado de direito internacional dos direitos humanos, 1997, p 390.

5 SILVEIRA, V. O. da; ROCASOLANO, M. M. Direitos humanos: conceitos, significados e funçôes, 2010, p. 191 
É neste cenário que se passa a analisar os direitos das minorias, especificamente, LGBTI, no âmbito internacional da Organização das Nações Unidas e da OEA - Organização Estados Americanos.

\section{SISTEMA INTERNACIONAL DIREITOS HUMANOS LGBTI - ONU}

Inicialmente, cumpre-se destacar o que tem sido realizado no sistema internacional de Direitos Humanos em prol da população LGBTI. Tanto no sistema global (ONU - Organização das Naçôes Unidas), quanto nos sistemas regionais ocidentais (africano, europeu e interamericano), as pessoas LGBTI passaram a ter seus direitos reconhecidos enquanto membros da família humana.

A descriminalização de relaçôes sexuais consentidas, a equiparação, para heterossexuais e LGBTI, da idade de consentimento, a proibição da discriminação no emprego, a legislação contra os crimes de ódio e/ou incitaçáo destes, o casamento civil ou as unióes civis e a adoção passaram a integrar o patrimônio jurídico destas populaçóes.

A Declaração Universal dos Direitos Humanos, publicada em 1948, afirmou que todos os seres humanos, não alguns, não a maioria, mas sim todos (grife-se), nascem livres e iguais em dignidade e direitos. Em consequência disso, a luta para concretizar os ideais da Declaração é o cerne da missão das Nações Unidas. A comunidade internacional tem construído um forte histórico de combate ao racismo, promoçáo da igualdade de gêneros, proteçáo das crianças e quebra das barreiras enfrentadas por pessoas com deficiência. No âmbito da ONU, houve inovaçôes importantes, sobre as quais far-se-á um sucinto histórico.

Em 2011, o Conselho de Direitos Humanos adotou a primeira Resoluçâo (17/19) da ONU sobre direitos humanos, orientaçáo sexual e identidade de gênero, expressando grave preocupaçáo com a violência e a discriminação contra as pessoas LGBTI. Firmouse no referido documento que acabar com a violência e a discriminação contra indivíduos em razão de sua orientação sexual e identidade de gênero é um grande desafio dos direitos humanos.

A Resolução foi aprovada por uma margem pequena de votos dos integrantes do Conselho, mas recebeu significativo suporte dos membros do Conselho de todas as regiōes. Sua adoção abriu caminho para o primeiro relatório oficial das Naçôes Unidas sobre o assunto, 
preparado pelo Escritório do Alto Comissariado para os Direitos Humanos. Conforme dados disponibilizados à época pela Organização das Naçôes Unidas:

O relatório do Alto Comissariado apresentou evidência de um padráo de violência sistemática e de discriminaçáo dirigidas às pessoas em todas as regiốes em razão da sua orientaçẫo sexual e identidade de gênero - desde discriminação no emprego, na assistência médica e educaçáo, à criminalização e ataques físicos seletivos, até mesmo assassinatos. O relatório incluiu um conjunto de recomendaçôes dirigidas aos Estados designados para fortalecer a proteção dos direitos humanos de lésbicas, gays, bissexuais e transgêneros (LGBT). (Relatório do Alto Comissariado das Naçóes Unidas para os Direitos Humanos, "Leis Discriminatórias, Práticas e Atos de Violência contra Indivíduos em Razáo de sua Orientaçáo Sexual e Identidade de Gênero) (A/HCR/19/41).

Desta forma, o relatório passa a ter importante destaque no cenário dos direitos humanos internacionais vez que orienta aos Estados a obrigação de proteger os direitos humanos de pessoas LGBT e intersex no regime internacional de direitos humanos baseado na Declaração Universal dos Direitos Humanos e, posteriormente, manifestados em tratados internacionais sobre o tema. Todas as pessoas, independente de sexo, orientação sexual ou identidade de gênero, têm direito de gozar da proteção assegurada pelo regime internacional dos direitos humanos, inclusive em relação aos direitos à vida, à segurança pessoal e à privacidade, o direito de ser livre de tortura, detençôes e prisões arbitrárias, o direito de ser livre de discriminação e o direito às liberdades de expressão, de reunião e de associação pacífica.

Observa-se que, a ONU, em seus inúmeros documentos elaborados em proteção das populaçôes vulneráveis, menciona as pessoas LGBTI. No que tange à violência física (agressōes, assassinatos, etc.), a Assembleia Geral das Naçóes Unidas, em uma série de resoluçôes, urgiu aos Estados que "garantissem a proteção do direito à vida de todas as pessoas sob sua jurisdição” e investigassem, rápida e completamente todos os assassinatos, incluindo aqueles motivados pela orientação sexual da vítima. (Assembleia Geral, resolução 57/214, 18 dezembro de 2002, par. 6; resolução 61/173, 16 de dezembro de 2006, par. 5(b); resolução 65/208, 21 de dezembro de 2010, par. 6.)

Outras manifestaçôes do Comitê dos Direitos Humanos da ONU podem ser citadas: O Comitê de Direitos Humanos também fez declaraçôes semelhantes em relação à Mongólia, afirmando que o Estado deve assegurar que pessoas LGBT tenham acesso à justiça e que todas as alegaçóes de ataques e ameaças contra indivíduos por causa de sua orientaçáo 
sexual ou identidade de gênero sejam completamente investigadas. (Observaçôes finais do Comitê de Direitos Humanos sobre a Mongólia (CCPR/C/MNG/CO/5), par.9; México (CCPR/C/MEX/CO/5), par. 21.)

No que diz respeito a proibir discriminação baseada em orientação sexual e identidade de gênero, a Declaraçáo Universal dos Direitos Humanos, o Pacto Internacional sobre Direitos Civis e Políticos e o Pacto Internacional sobre Direitos Econômicos, Sociais e Culturais incluem listas de condições proibidas para discriminação em suas garantias de não discriminação. Essas listas não incluem explicitamente orientação sexual ou identidade de gênero, mas todas terminam com as palavras qualquer outra condição. $\mathrm{O}$ uso da expressão qualquer outra condiçáo mostra que as listas tinham o objetivo de serem abertas e ilustrativas: em outras palavras, os motivos de discriminação não estáo fechados, ou seja, não são taxativos.

Para o Comitê de Direitos Econômicos, Sociais e Culturais, a natureza da discriminação varia de acordo com o contexto e evolui com o tempo. Uma abordagem flexível para a expressão qualquer outra condiçáo é, portanto, necessária, a fim de se capturar outras formas de tratamento diferencial que não podem ser razoáveis e objetivamente justificadas e sáo de natureza comparável aos motivos expressamente reconhecidos no artigo 2, parágrafo 2. Esses motivos adicionais são geralmente reconhecidos quando refletem a experiência de grupos sociais vulneráveis que sofreram e continuam a sofrer marginalização. (Comitê de Direitos Econômicos, Sociais e Culturais, Comentário Geral no 20, par. 27).

Portanto, a orientaçẫo dos Órgãos das Naçôes Unidas é no sentido de que os Estados devem efetivamente investigar, processar e punir os criminosos responsáveis por execuçôes extrajudiciais e decretar leis que criminalizem o ódio e que protejam o indivíduo da violência baseada na orientação sexual e na identidade de gênero. Sistemas eficientes devem ser estabelecidos para registrar e relatar atos de violência motivados pelo ódio.

\section{SISTEMA INTERAMERICANO DE DIREITOS HUMANOS E DIREITOS LGBTI}

O Sistema Interamericano de Direitos Humanos possui importante documento editado em 2008, consistente na notável Resolução 235/2008 que possui como título Direitos Humanos, Orientação Sexual e Identidade de Gênero (aprovada em 03 de junho de 2008). 
Nessa oportunidade, a Assembleia Geral determinou, em procedimento instaurado pelo Brasil, que a Comissão de Assuntos Jurídicos e Políticos (CAJP) deveria incluir o tema Direitos humanos, Orientaçáo Sexual e Identidade de Gênero em sua agenda e, ainda, que o Conselho Permanente informasse a Assembleia-Geral sobre a implementaçáo da resolução, com a devida disponibilização de recursos financeiros para tanto. ${ }^{6}$

Posteriormente, em 2009, foi editada a Resolução 2504 em que foi reiterada a preocupação com as violaçôes dos direitos humanos motivadas pela orientação sexual e pelo gênero, aconselhando aos Estados membros, da qual o Brasil faz parte, que:

a) condena a violência perpetrada contra pessoas LGBTI;

b) insta os Estados-membros a investigar e responsabilizar os autores de condutas ilícitas com base na orientação sexual e identidade de gênero da vítima;

c) solicita aos Estados-membros assegurar proteção adequada aos defensores de direitos humanos que militam com a violência e as violaçóes de direitos humanos cometidos contra indivíduos em virtude de sua orientação sexual e identidade gênero;

d) requer à $\mathrm{CIDH}$ e demais órgãos do SIDH a dispensarem atençẫo a essa temática;

e) CAJP incluir o tema Direitos Humanos, Orientação Sexual e Identidade de Gênero em sua agenda;

f) por fim, insta o Conselho Permanente que informe o processo de implementação do documento à Assembleia-Geral, subsidiado com os recursos financeiros necessários para tanto. $^{7}$

Outras Resoluçôes foram editadas, tais como a Resolução no . 2653/2011, a Resolução no. 2721/2012, a Resoluçáo no. 2807/2013, sendo que o conteúdo de todas elas orienta que os Estados membros tenham política eficiente no combate à intolerância, bem como incentivo à promoção dos direitos LGBTI.

Urge-nos, neste ponto informar a importante Convenção Interamericana contra Toda Forma de Discriminação e Intolerância, aprovada em 5 de junho de 2013. Tal Convenção

$\overline{6}$ ORGANIZAÇÃO DOS ESTADOS AMERICANOS, 2008, p. 01.

7 ORGANIZAÇÃO DOS ESTADOS AMERICANOS, 2009a, pp. 01-02. 
é um marco histórico, sendo o primeiro documento juridicamente vinculante que, de forma expressa, condena a discriminação baseada em orientação sexual, identidade e expressão de gênero. ${ }^{8}$

Em linhas gerais, a referida convenção traz os conceitos de discriminação e discriminação indireta que tenha por base a nacionalidade, idade, sexo, orientaçáo sexual, identidade e expressão de gênero, idioma, religião, identidade cultural, filosofia política ou de outra natureza, origem social, posição socioeconômica, nível educacional, condição de migrante, refugiado, repatriado, apátrida ou deslocado interno, deficiência, característica genética, estado de saúde física ou mental, inclusive infectocontagioso, e condição psíquica incapacitante, ou qualquer outra condição (art. 1\%). A Convenção também reafirma o princípio da igualdade e da não-discriminação $\left(\right.$ art. $2^{\circ}$ ) e que todo ser humano goza do direito ao reconhecimento, exercício e proteção, em condiçóes de igualdade, individual e coletivamente, de seus direitos humanos e liberdades fundamentais previstos na legislação interna e nos instrumentos internacionais aplicáveis.

Destaca-se que o Estado Brasileiro assinou a referida declaração, todavia o Congresso Nacional ainda não submeteu o documento aos trâmites legais para que surta os efeitos jurídicos legais no Estado Interno?.

\section{DEFENSORIAS PÚBLICAS NO BRASIL E DIREITOS INTERNACIONAIS CONSAGRADOS À POPULAÇÃO LGBTI}

Em virtude das Declaraçôes, Resoluçôes e recomendaçôes internacionais, a partir de 2013, no Brasil, a Secretaria de Direito Humanos da Presidência da República divulgou o segundo relatório sobre homofobia e transfobia, com dados referentes ao ano de 2012, no qual apontou: foram registradas 9.982 violaçóes de direitos contra LGBTI (aumento de $166 \%$ em relação a 2011), das quais 310 foram homicídios (em 2011, foram 278); no tocante às vítimas, a grande maioria é do sexo masculino (71\%), gay (60,44\%) e com idade entre 15 e 29 anos $(61,33 \%)$ e, a maioria dos autores é conhecida da vítima (51\%), tais como familiares e vizinhos, sendo que $25,54 \%$ das violaçôes ocorreram nas casas da vítima e $30 \%$ nas ruas. ${ }^{10}$

8 ORGANIZAÇÃO DOS ESTADOS AMERICANOS, $2013 \mathrm{~d}$.

9 É preciso realizar o processo de ratificação dessa convenção com a aprovação pelo Congresso Nacional Brasileiro, na forma do parágrafo $3^{\circ}$ do art. $5^{\circ}$ da $\mathrm{CF}$ e o posterior depósito do instrumento ratificado na Secretaria Geral dos Estados Americanos.

$10 \quad$ BRASIL, 2013b, pp. 18 e ss. 
Diante de índices estatísticos altos, que denotam violência, preconceito, restrição de direitos fundamentais em face da população LGBTI, impōe-se uma política governamental mais efetiva e eficaz para implementação de direitos.

No âmbito nacional, criou-se o Conselho Nacional de Combate à Discriminação (Decreto 3952) e Proteção dos Direitos de Lésbicas, Gays, Bissexuais, Travestis e Transexuais, sendo um órgão colegiado, vinculado à Secretaria de Direitos Humanos da Presidência da República. Posteriormente, por meio do Decreto 7.388/2010, institui-se o Conselho Nacional de Combate à Discriminação LGBTI.

O referido Conselho é composto por 30 membros, sendo 15 governamentais e 15 da sociedade civil, e tem por atribuiçáo participar da elaboraçáo de critérios e parâmetros de ação governamental que visem a assegurar as condiçôes de igualdade à população LGBTI.

Nesse sentido, adentra-se no aspecto da Defensoria Pública Brasileira como agente transformador da realidade social e implementação de direitos às minorias esquecidas.

Como cediço, a Defensoria Pública no Brasil foi criada dentre outras finalidades, a implementação de políticas inclusivas cumprindo exatamente o que determina a Constituição Federal em seu art. $5^{\circ}$ que assegura: 'Todos sáo iguais perante a lei, sem distinção de qualquer natureza, garantindo-se aos brasileiros e aos estrangeiros residentes no País, a inviolabilidade do direito à vida, à liberdade, à igualdade, à segurança e à propriedade. " (grifa-se). ${ }^{11}$

E no inciso LXXIV, que afirma: "O Estado prestará assistência jurídica integral e gratuita aos que comprovarem insuficiência de recursos" (CF,1988). Quando se refere ao que não possui hipossuficiência de recursos, entenda-se, recursos financeiros, bem como insuficiência organizacional para implementação dos direitos de categorias que do ponto de vista estrutural são hipossuficientes.

Pode-se afirmar entáo, que a Defensoria Pública também é um meio pelo qual o indivíduo conhece e reconhece seus direitos, suas obrigaçóes, abrangendo, assim, assistência e consultoria. Isto é o que se define como democracia no mundo jurídico. É por meio dela que, os desamparados e as minorias possuem a noçáo de cidadania e de suas funçóes de cidadãos.

$\overline{11 \quad \text { BRASIL,2015 }}$ 
Resta-nos claro que a Constituição Federal Brasileira optou por um sistema de assistência jurídica que tutele direitos das minorias. A Defensoria Pública tem como missão a orientação jurídica, a promoção dos direitos humanos e a defesa dos direitos individuais e coletivos, de forma integral e gratuita aos necessitados.

Especificamente em relação às minorias, a Organização das Naçôes Unidas as classificou em duas espécies: minorias by force e minorias by will. Explica-se:

Entende-se por minoria by force "aquelas minorias e seus membros que se encontram numa posição de inferioridade na sociedade em que vive e que aspiram apenas a nâo serem discriminados em relação ao resto da sociedade, querendo adaptar e assimilar-se a esta. Em contrapartida, as minorias by will e seus membros exigem, além de não serem discriminados, a adoção de medidas especiais as quais permitam-lhes a preservação de suas características coletivas, culturais, religiosas ou linguísticas. ${ }^{12}$

Assim, os grupos LGBTI podem ser incluídas no conceito de minoria by force, vez que pleiteiam a equiparaçấo de direitos concedidos às pessoas heterossexuais.

A defesa das minorias, especificamente dos LGBTI, significa sinônimo de combate à intolerância, que se manifesta de várias maneiras no segmento. Desta feita, a inclusão social deste grupo de minorias deve ser urgentemente efetivada, não só em respeito à prevalência dos direitos humanos, mas também para que essas pessoas contribuam para a construção e manutenção da sociedade em que vivem.

O instrumento que pode ser utilizado pela Defensoria para a implementação destes direitos é a tutela coletiva, tão sabiamente concedida pela Lei $11.448 / 2007$, dando legitimidade para que o órgão proponha ações civis públicas em prol dos necessitados economicamente, bem como àqueles necessitados do ponto de vista organizacional. Conforme nos ensina Boson:

Isso significa dizer que, entendida a possibilidade jurídica de atuação pela Defensoria como um instrumento para a efetivação do próprio direito material, e considerando que o titular do direito protegido pela Instituição é um sujeito/grupo vulnerável, assegurar condiçôes fáticas e jurídicas para a possibilidade real de atuação da Defensoria Pública significa, em proporção direta, proteger as pessoas mais vulneráveis. É esta inclusive a razão pela qual não se deve limitar, como insistem

12 WUCHER, Gabi. Minorias: proteção internacional em prol da democracia. 2000, p. 46 
em fazer alguns desavisados, a atribuição da Instituição na defesa dos necessitados apenas no sentido de hipossuficiência econômica. Os contornos constitucionais dados à Defensoria Pública, bem assim as previsôes contidas em sua respectiva Lei Orgânica, não permitem tal exegese minimalista. Ao revés, o que deve nortear a análise da atribuição da instituiçáo é a ideia do exercício pleno da cidadania. Daí porque qualquer vulnerabilidade dá margem à atuação da instituição. ${ }^{13}$

É neste contexto que surge o papel primordial da Defensoria Pública de implementar as recomendaçôes advindas dos organismos internacionais na consecução da igualdade entre gênero, auxiliando o Estado Brasileiro a garantir direitos de igualdade, nome, segurança, vida, saúde, previdência, assistência à população LGBTI.

Menciona-se o fato de que, cotidianamente, os Defensores Públicos de todo o país recebem demandas atinentes à populaçáo LGBTI referente à discriminação em vários aspectos, homicídio e agressão advindos de homofobia e transfobia, direitos previdenciários, assistenciais, saúde, etc.

Consectários da igualdade de direitos e efetiva proteção à população LGBTI urgenos comentar que competirá a essa entidade governamental repudiar toda forma de discriminação baseada em gênero.

Isto porque, não só a orientação sexual e a identidade de gênero são alvos do descaso do legislador, mas também os vínculos homoafetivos não dispõem de reconhecimento legal. A Constituição reconhece a família como base da sociedade. E, apesar de concederlhe especial proteção, faz referência expressa ao casamento, à união estável e à família monoparental. Do mesmo modo, recomenda a transformação em casamento somente a união estável formada por um homem e uma mulher. Tal, no entanto, não significa que a uniâo homoafetiva não é uma entidade familiar e nem quer dizer que não lhe é concedida especial proteção.

Diante das recomendaçóes internacionais anteriormente mencionadas, não há dúvidas de que existe um direito subjetivo à livre orientação sexual e à identidade de gênero. Via de consequência, há o dever jurídico de esse direito ser reconhecido e respeitado, impondo-se tal dever a Defensoria Pública.

13 BOSON, É. P. A defensoria pública como instituição articuladora do direito como padrão de reconhecimento. Revista da Defensoria Pública da Uniáo, Defensoria Pública da União, 2013, p. 14. 
Vê-se, pois, que é histórica a omissão do Estado no que diz respeito aos direitos das pessoas homossexuais, lésbicas, bissexuais, transexuais, travestis e intersexuais. A perseguição de que são alvo acabou por condená-los não só à invisibilidade. O resultado é muito mais perverso, pois os deixa refém de práticas homofóbicas, sendo colocados em situaçáo de absoluta vulnerabilidade social.

Necessário, pois, acabar com a invisibilidade jurídica de segmento da população, que é alvo de perversa discriminação em razão da orientação sexual e da identidade de gênero. Impóe-se verdadeira mudança de paradigma a toda a sociedade. Todos precisam aprender a conviver com a diferença. Não só no mundo público, mas nos mais diversos segmentos da iniciativa privada. A postura omissiva, que acabava por chancelar o assédio social e moral na escola, no ambiente de trabalho, não mais tem espaço diante de açôes perpetradas pelos defensores públicos de todo o país.

Destarte, a Defensoria Pública, como Instituição autônoma e independente, deve promover a inclusão de todos, combater a discriminação e a intolerância por orientação sexual ou identidade de gênero e criminalizar a homofobia, a lesbofobia, a bifobia e a transfobia ${ }^{14}$, de modo a garantir a efetivação da igualdade de oportunidades defende tais direitos por meio de açóes coletivas protetivas dos direitos difusos e individuais.

O Defensor Público, ao defender tais direitos, estará promovendo princípios constitucionais elementares como o da dignidade da pessoa humana; igualdade e respeito à diferença; liberdade à livre orientação sexual e identidade de gênero; reconhecimento da personalidade de acordo com a identidade de gênero; convivência comunitária e familiar; liberdade de constituiçấo de família e de vínculos parentais; respeito à intimidade, à privacidade e à autodeterminação e direito fundamental à felicidade.

Propóe-se que as Defensorias Públicas de todo o país constituam comissões ou grupos de

14 Homofobia é uma série de atitudes e sentimentos negativos em relação a pessoas homossexuais, bissexuais e, em alguns casos, contra transgêneros e pessoasintersexuais. As definiçōes para o termo referem-se variavelmente a antipatia, desprezo, preconceito, aversão e medo irracional. Lesbofobia (ou lesbifobia) inclui várias formas de negatividade em relação às mulheres lésbicas como indivíduos, como um casal ou como um grupo social. Com base nas categorias de sexo ou gênero biológico, orientação sexual, identidade lésbica e expressão de gênero, esta negatividade engloba preconceito, discriminaçáo e abuso, além de atitudes e sentimentos variando de desdém a hostilidade. Bifobia é um termo usado para descrever o medo de, aversão à, ou discriminação contra bissexualidade ou pessoa LGBT que é bissexual ou percebe ser bissexual. A transfobia é uma série de atitudes ou sentimentos negativos em relação às pessoas travestis, transexuais e transgêneros. 
trabalho que possam defender os direitos LGBTI em vários espectros. À entidade compete lutar pelo amplo respeito ao Direito a igualdade e não discriminação, impedindo distinção, exclusão, restrição ou preferência que tenha por objetivo anular ou limitar direitos e prerrogativas garantidas aos demais cidadãos. Lutar contra práticas discriminatórias que impeçam o ingresso ou a permanência em estabelecimento público, ou estabelecimento privado aberto ao público.

Quanto ao Direito de Sucessão e à convivência familiar, urge-se que as Defensorias estejam atentas em proteger o direito ao casamento, o direito à constituição de união estável e sua conversão em casamento, o direito à escolha do regime de bens, o direito ao divórcio, o direito à filiação, à adoção e ao uso das práticas de reprodução assistida, o direito à proteção contra a violência doméstica ou familiar, o direito à herança, ao direito real de habitação e ao direito à concorrência sucessória, bem como os importantes direitos previdenciários.

Aos Transexuais, Travestis e Intersexuais deve ser garantido, por meio de açóes afirmativas, a livre expressão de sua identidade de gênero, sendo assegurado o uso das dependências e instalaçóes correspondentes à identidade de gênero. Os procedimentos médicos, cirúrgicos e psicológicos destinados à adequação do sexo morfológico à identidade de gênero devem ser uma bandeira diária da atuaçáo da Defensoria Pública. Além disso, direitos inerentes ao nome social devem ser preservados em todos os órgãos públicos $\mathrm{da}$ administração direta e indireta, nas esferas federal, estadual, distrital e municipal; em fichas cadastrais, formulários, prontuários, entre outros documentos do serviço público em geral; nos registros acadêmicos das escolas de ensino fundamental, médio e superior.

No que se refere ao direito à Saúde, às Defensorias Públicas compete lutar para que seja garantido o acesso aos serviços universais e igualitários do Sistema Único de Saúde - SUS, independentemente de orientação sexual ou de identidade de gênero.

Enfim, inúmeros outros direitos poderiam ser citados como função indispensável do Defensor Público na proteção das minorias LGBTI, sendo, pois, aconselhável a criação de Grupos de Trabalho ou Comissôes no âmbito das Defensorias Públicas de todo país, objetivando atender às demandas que são trazidas pelo público mencionado neste trabalho.

Em virtude disso, no âmbito da Defensoria Pública da União, criou-se um grupo de trabalho DPU - LGBTI (Portaria no. 501, de 01 de outubro de 2015) visando a implementar as diretrizes internacionais, bem como a auxiliar no combate à violência e à intolerância 
quanto ao gênero, competindo ao referido grupo, dentre outras atribuiçôes, promover a defesa dos direitos da população LGBTI; fomentar a educação em direitos LGBTI e o enfrentamento do preconceito e da discriminação; salvaguarda dos direitos da população LGBTI em situação de prisão; monitorar casos sensíveis relacionados ao enfrentamento do preconceito contra a populaçáo LGBTI, podendo realizar os encaminhamentos e recomendaçóes que entender cabíveis.

Alguns projetos instaurados pelo Grupo de Trabalho LGBTI - DPU já obtiveram sucesso, como recomendaçóes expedidas implementando nome social para travestis e transexuais em órgãos do Governo Federal, especificamente Ministério do Trabalho, Universidades Federais e dentro da própria Defensoria Pública da União.

Ademais, o referido grupo de trabalho expediu recomendação ao Ministério da Saúde objetivando a retirada da proibição de doação de sangue de homens que fizeram sexo com outros homens, por entender que tal comando é totalmente preconceituoso ferindo princípio elementar da não discriminação.

Neste mister, não pode furtar-se o Defensor Público, em não tutelar os referidos direitos sob pena de descumprir a digna função que lhe é outorgada, de proteger as minorias.

Diante de todos esses direitos defendidos pelas Defensorias Públicas, urge-se que a referida Instituição passe a compor como membro do Conselho Nacional de Combate à Discriminação, o que, infelizmente não foi concedido pelo Decreto 7.388/2010. A inclusão da Defensoria Pública é medida que se impóe como forma de tratamento igualitário a todas as minorias LGBTI do Brasil.

\section{CONSIDERAÇÓES FINAIS}

Portanto, diante das determinaçôes internacionais, baseadas nas três dimensões dos direitos humanos, tanto no sistema global de direitos humanos (ONU), quanto no sistema regional (OEA), os Estados são obrigados a garantir a não discriminação no exercício de todos os direitos humanos para todas as pessoas, independentemente de orientação sexual ou identidade de gênero. Essa é uma obrigação imediata e transversal perante o regime internacional de direitos humanos. Referida diretriz faz com que as Defensorias Públicas, órgáos incumbidos de prestarem assistencia jurídica integral e gratuita às minorias, 
implementem políticas objetivando garantir direitos fundamentais básicos à população LGBTI.

Os Defensores Públicos não podem permitir que abusos contra Direitos Humanos continuem sendo perpetrados, sendo necessária atuação eficaz, no sentido de que práticas discriminatórias sejam banidas do ordenamento jurídico Brasileiro.

Garantir direitos de natureza civil e penal, que assegurem uma série de direitos a homossexuais, lésbicas, bissexuais, transexuais, travestis e intersexuais, do mesmo modo imponha o reconhecimento jurídico das uniōes homoafetivas e criminaliza a homofobia, e realizar políticas públicas de inclusão, nada mais é do que cumprir a ordem jurídica internacional.

Nos termos do art. 134 da CF, foi expressamente atribuída à Defensoria Pública, a orientação jurídica e a defesa em todos os graus dos necessitados como expressão e instrumento do regime democrático, a promoçâo dos direitos humanos e a defesa, em todos os graus, judicial e extrajudicial, dos direitos individuais e coletivos, de forma integral e gratuita.

A Defensoria Pública representa, assim, no contexto brasileiro, a instituição a quem o constituinte confiou a promoçáo dos direitos humanos e a defesa, em todos os graus, integral e gratuita, dos necessitados ou vulneráveis.

O instrumento jurídico processual para se proteger os direitos reconhecidos internacionalmente à comunidade LGTI é o Estatuto Jurídico da Tutela Coletiva, que atribui legitimidade às Defensorias Públicas para atuarem. Com efeito, a Lei Complementar $\mathrm{n}^{\circ}$. 80, bem como o Novo Código de Processo Civil, atribui expressamente o dever da Defensoria Pública de atuar coletivamente.

O sistema normativo brasileiro, tendo presente valores sociais suscetíveis de proteção estatal e, observando, ainda, uma tendência que se verifica no âmbito do direito comparado no sentido da coletivização dos instrumentos de índole processual, necessário instituir mecanismos ágeis destinados a viabilizar de modo eficaz a imediata tutela jurisdicional dos interesses metaindividuais.

Enfatiza-se que todos os grupos, sejam maioria, ou minorias, têm direito a ter direitos, uma prerrogativa básica que se qualifica como fator de viabilizaçáo de direitos essenciais, 
tais como liberdade, igualdade, dentre outros, que deve assistir a qualquer pessoa especialmente àquelas que são excluídas.

No âmbito da Defensoria Pública da União, a tendência à implementação dos direitos internacionais LGBTI está tendo avanço, com a criação dos grupos de trabalho LGBTI, que já têm atuado em várias frentes para promoção de tais direitos, tais como a implementação do nome social para Travestis e Transexuais, bem como na modificação da Portaria que veda a doação de sangue para homens que fazem sexo com homens. Da mesma forma, na Defensoria Pública do Estado de Sáo Paulo, criou-se o Núcleo Especializado de Combate à Discriminação, Racismo e Preconceito, que, também, atua promovendo direitos e respeito aos direitos LGBTI.

$\mathrm{O}$ acesso à justiça dos direitos internacionais deve ser maximizado, tratando-se, portanto, de uma legitimidade concorrente entre as Defensorias Públicas da União, dos estados e do Distrito Federal.

Conclui-se que, no Estado Brasileiro, marcado por inegáveis e graves desníveis sociais, alto índice de preconceito, a função da Defensoria Pública afigura-se essencial para implementaçấo da inclusão e promoção dos direitos internacionais LGBTI.

\section{REFERÊNCIAS}

ASOKAN, S. Suprema Corte da Índia volta a tornar sexo gay ilegal. Reuters, $11 \mathrm{dez}$. 2013. Disponível em: Acesso em: 15 abr. 2014.

BAHIA, A. G. M. F. Homofobia no Brasil, resoluçôes internacionais e a Constituição de 1988. Jus Navigandi, Teresina, ano 17, n. 3269, 13/06/2012. Disponível em: Acesso em: 15 abr. 2014.

BOBBIO, N. et al. A era dos direitos. 1. ed. Rio de Janeiro: Campus, 2004.

BORRILLO, D. Homofobia: história e crítica de um preconceito. Belo Horizonte: Autêntica, 2010.

BOSON, É. P. A defensoria pública como instituição articuladora do direito como padrão 
de reconhecimento. Revista da Defensoria Pública da Uniáo, Defensoria Pública da Uniāo, Brasília, n. 6, dez. 2013. Disponível em: <http://www.dpu.gov.br/escola/images/ revistadpu/revista_06.pdf>. Acesso em: 20 abr. 2016.

BRASIL. CONSELHO FEDERAL DE PSICOLOGIA. Resolução CFP n. 001/99, de 22 de mar. de 1999. Disponível em: < http://site.cfp.org.br/wp-content/uploads/1999/03/ resolucao1999_1.pdf>. Acesso em: 20 mai. 2016.

GUIMARÃES, A. F. P. O desafio histórico de "tornar-se um homem homossexual": um exercício de construção de identidades. Temas psicol. Vol 17, n. 2, Ribeirão Preto, 2009. Disponível em: <http://pepsic.bvsalud.org/scielo.php?script=sci_arttext\&pid=S1413389X2009000200023>. Acesso em: 20 mai. 2015.

LAFER, C. A reconstrução dos Direitos Humanos: a contribuição de Hannah Arendt. Disponível em: http://www.scielo.br/pdf/ea/v11n30/v11n30a05.pdf; Acesso em 14 set. 2016.

ORGANIZAÇÃO DOS ESTADOS AMERICANOS. Assembleia general. Resolución n. 2721, de 04 de jun. de 2012. Derechos humanos, orien-tación sexual e identidad y expresión de gênero. Disponível em: <http://www.oas.org/dil/esp/AG-RES_2721_ XLII-O-12_esp.pdf>. Acesso em: 15 abr. 2014.

WUCHER, G. Minorias: proteção internacional em prol da democracia. São Paulo: Juarez de Oliveira, 2000.

RIVERO, M. I. Patologización: ser lesbiana, gay, bisexual y/o trans no es una enfermedad. Disponível em: <http://www.oas.org/es/cidh/prensa/comunicados/2016/064.asp>. Acesso em: 25 mai. 2016.

SILVEIRA, V. O. da; ROCASOLANO, Maria Mendez. Direitos humanos: conceitos, significados e funçóes. São Paulo: Saraiva, 2010

SCHAFER, J. Classificação dos direitos fundamentais - do sistema geracional ao sistema unitário. Porto Alegre: Livraria do Advogado. 2005 
